\title{
Simplified nonlinear rotational inertia model for the simulation and analysis of the characteristics of an unconventional VAWT type wind turbine with variable pitch
}

\section{Modelo de inercia rotacional no lineal simplificado para la simulación y el análisis de las características de un aerogenerador de tipo VAWT no convencional de paso variable}

FRANCO-MARTÍNEZ, David †*, GARCÍA-BARRERA, Jesús, DÍAZ-SALGADO, Jorge and HUERTA-CHÁVEZ, Oliver M.

Centro Tecnológico, Facultad de Estudios Superiores Aragón, UNAM

Tecnológico de Estudios Superiores de Ecatepec, 55210 Ecatepec de Morelos, Edo. De México, México

Tecnológico de Estudios Superiores de Tianguistenco, 52650 Tianguistenco, Edo. De México, México

ID $1^{\text {st }}$ Author: David, Franco-Martinez / ORC ID: 0000-0002-0464-8504, CVU CONACYT ID: 69978

ID $1^{\text {st }}$ Co-author: Jesús, García-Barrera / ORC ID: 0000-0003-4776-4473

ID $2^{\text {nd }}$ Co-author: Jorge, Díaz-Salgado / ORC ID: 0000-0002-0548-437X, CVU CONACYT ID: 43309

ID $3^{\text {rd }}$ Co-author: Oliver M., Huerta-Chávez / ORC ID: 0000-0002-2932-2033, CVU CONACYT ID: 105579

DOI: $10.35429 / J T D .2021 .15 .5 .11 .22$

Received March 26, 2021; Accepted June 28, 2021

\section{Abstract}

This paper shows a double multiple stream tube model coupling to a rotational inertia model. It allows the simulation and analysis of the characteristics of an unconventional vertical-axis wind turbine (VAWT) with Variable Pitch. This implementation permits to employ a stationary response of the wind turbine calculated across the main characteristics of output torque based on experimental aerodynamic coefficients and the Reynolds at each station, can be transformed into a transient response by a simplified non-linear rotational inertia dynamic model to predict the startup, idle, stabilization and sudden stop of our device.

VAWT, Variable pitch angle, Multiple stream tube model, Rotational inertia

\begin{abstract}
Resumen
Este trabajo se presenta una técnica numérica del método de múltiples tubos de corriente estacionarioacoplada a un modelo de inercia rotacional, para la simulación y análisis de las características de un aerogenerador tipo VAWT no Convencional con Paso Variable. Dicha implementación permite que una respuesta estacionaria del aerogenerador calculada a través de las principales características de torque de salida basados en coeficientes aerodinámicos experimentales y el Reynolds de cada estación, pueda ser transformada en una respuesta transitoria a través de un modelo dinámico de inercia rotacional no lineal simplificado para el pronóstico de la puesta en marcha, ralentí, estabilización y paro repentino de nuestro dispositivo.
\end{abstract}

VAWT, Ángulo de paso variable, Modelo de múltiples tubos de corriente, Inercia rotacional

Citation: FRANCO-MARTÍNEZ, David, GARCÍA-BARRERA, Jesús, DÍAZ-SALGADO, Jorge and HUERTA-CHÁVEZ, Oliver M. Simplified nonlinear rotational inertia model for the simulation and analysis of the characteristics of an unconventional VAWT type wind turbine with variable pitch. Journal of Technological Development. 2021. 5-15: 11-22

\footnotetext{
* Correspondence to Author (e-mail: davd_francom@hotmail.com)

$\dagger$ Researcher contributing first author
} 


\section{Introduction}

To date, several studies have investigated different aerodynamic models to describe the static behavior of the VAWT with straight blades type Darrieus. These models are suitable to identify the optimal design parameters, performance prediction, and standing behavior of a vertical-axis wind turbine [1].

Various studies have reported different mathematical models of vertical axis wind turbines, one of these and the most applied is the Double Multiple Stream Tube. It allows to obtain the wind turbine response in a steady state to find the torque average of a wind turbine [10]. The Vortex model was another important mathematical mode, it employed power flow models based on the calculation of the speed field around the wind turbine through the influence of vorticity on the wake formed by the blades [10]. Hirsch and Mandal reported the cascade model [10], it applied the principles of connecting two cascade subsystems to the VAWTs and can also be used for different turbomachine types.

Different theories exist in the literature regarding to the purely mechanical solutions and have been reported to improve the efficiency of the wind turbine. These solutions were proposed without any dynamic model of the wind turbine [20, 21 and 22]. Mechatronic solutions have also been stated and proposed a closed loop control of the pitch angle from the measurement of the turning angle. Unfortunately, these dynamic models were not complete, and their analysis were incomprehensible [16,17 and 18].

It is important to mention that these mechatronic solutions have concentrated on the pitch angle variation method. Because it has been recognized as an attractive solution to improve the performance of vertical axis wind turbines in a theoretical way. These improvements have mainly consisted of: (i) the analysis of the tangential force coefficient with both negative and positive fixed angles of the pitch angle, (ii) the analysis of the tangential force coefficient comparing fixed pitch angles vs optimized angles and (iii) the determination of the angular positions where the wind turbine has greater torque for a given pitch angle [10].

\section{Static Model}

2.1.- Model with a single stream tube (Single Stream tube Model). This model fundamentally contemplates that the wind speed $(\mathrm{V})$ is constant over the turbine [1], considering a single current tube (see Figure 1).

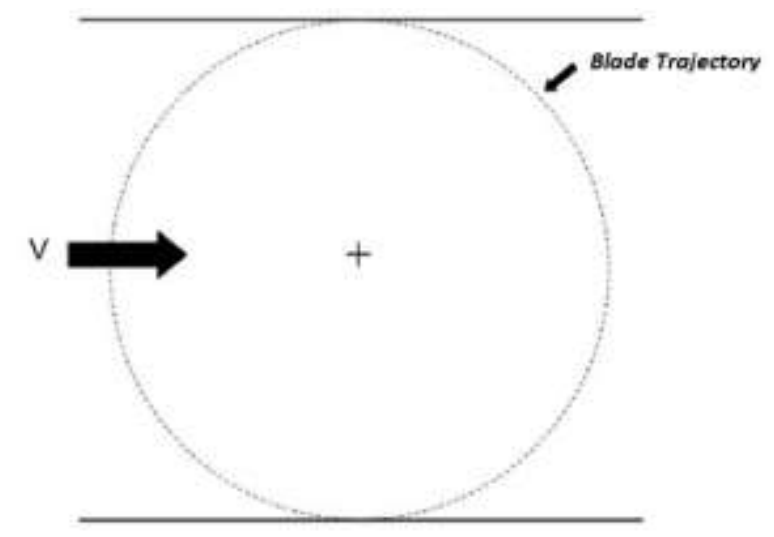

Figure 1 Single Stream tube Model Own Elaboration

According to the wind direction and angular position of each wind turbine blades in this single stream tube model can be defined: the angle of attack and the lift and drag forces and with them the lift and drag coefficients, respectively.

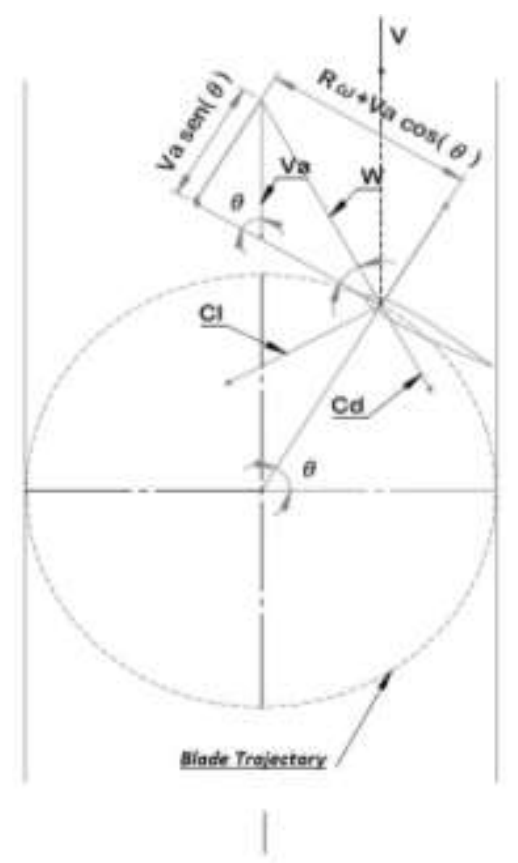

Figure 2 Single Stream tube and angle of attack components

Own Elaboration

The angle of attack $\alpha$ can be obtained by its geometric components, they are represented in Figure 2, so that: 
$\alpha=\tan ^{-1}\left(\frac{\mathrm{Va} \operatorname{sen}(\theta)}{\mathrm{R} \omega+\operatorname{Va} \cos (\theta)}\right)$

While the relative velocity $W$ is obtained by:

$W=\sqrt{(V a \operatorname{sen}(\theta))^{2}+(R \omega+V a \cos (\theta))^{2}}$

Based on the actuator disc model, the induced velocity $V_{a}$ can be defined as:

$V_{a}=V_{\infty}(1-a)$

Where $\omega$ is the angular velocity, $\theta$ the angular position and $\mathrm{a}$ is the induction factor. Correspondingly, the Normal $C_{n}$ and Tangential coefficients can be calculated $C_{t}$ through the $C_{d}$ and $C_{l}$ lift components, which are specific to each airflow (Figure 3), so that:

$$
\begin{aligned}
& C_{n}=C_{l} \cos (\alpha)+C_{d} \operatorname{sen}(\alpha) \\
& C_{t}=C_{l} \operatorname{sen}(\alpha)-C_{d} \cos (\alpha)
\end{aligned}
$$

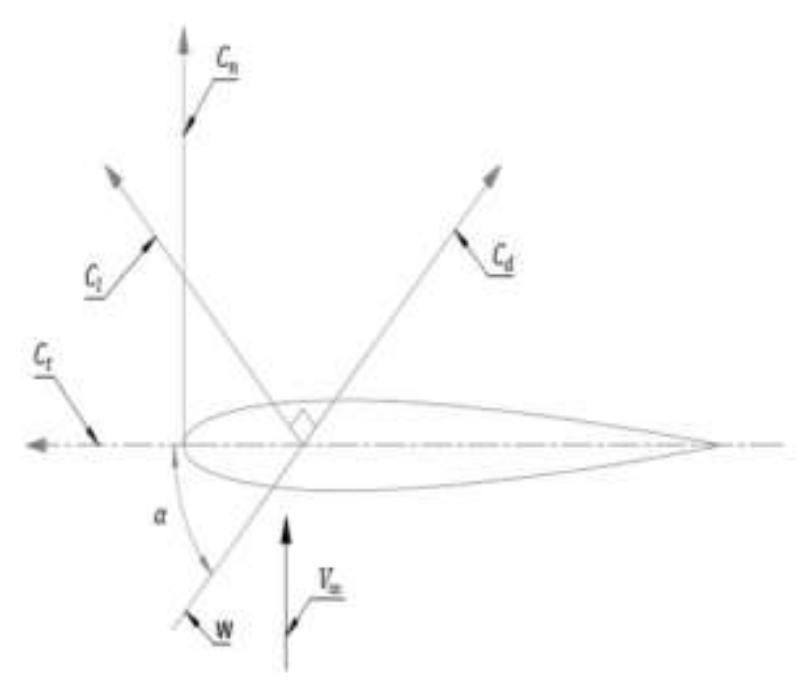

Figure 31 Coefficient Normal $\left(C_{n}\right)$ and Tangential $\left(C_{t}\right)$ acting on a blade

Own Elaboration

\subsection{Model of multiple stream tubes}

This model is the generalization of the singletube model by considering multiple stream tubes in the blade sweeping area. The main difference between this model and the single stream tube model is that for each stream tube there are different induction rates. This means that each stream tube has its own induction velocity (Figure 4). Therefore, the results are more accurate as more stream tubes are considered in the calculation of average wind turbine torque.

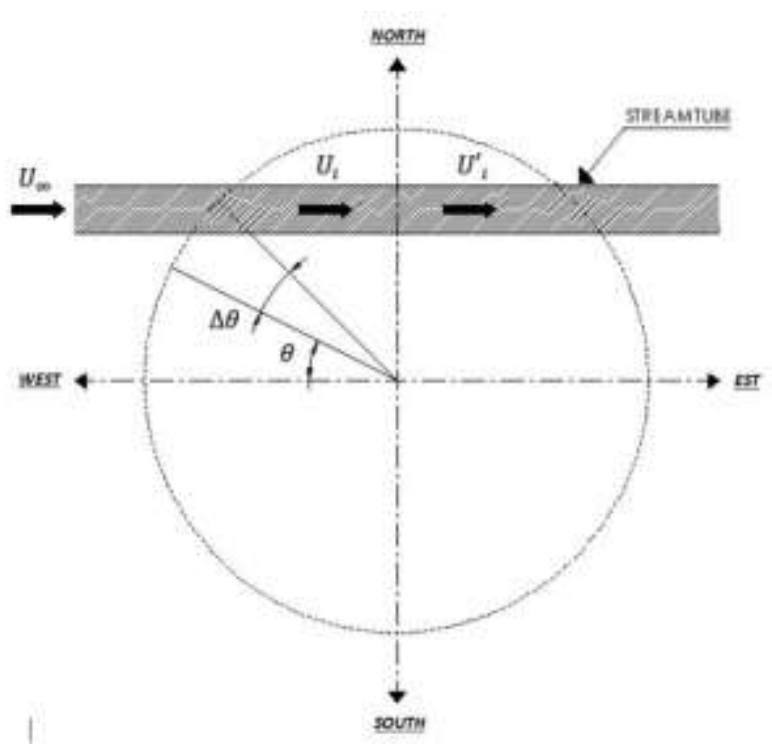

Figure 4 Multiple stream tube theory Own Elaboration

In the next section the double tube model with multiple airflow currents is used to establish a numerical model. It permits to obtain the forces and moments produced by the wind turbine blades from the input parameters both in a stationary and transient state.

\subsection{Implementation of the algorithm of the Double Multiple Stream Tube model}

This algorithm is employed to compute the average torque of a VAWT of straight blades from 3 main input parameters (Figure 5) which are: (i) air velocity $V_{\infty}$, (ii) angular velocity $\omega$, and (iii) radius of the wind turbine $R$.

By given these input parameters, the algorithm calculates angle of attack, and lift and drag coefficients (Figure 15) using a twodimensional interpolation, which are dependent on the Reynolds number. For each stream tube, an iteration process is performed to identify: (i) the induction factor $a$, (ii) the relative wind speed, (iii) the Reynolds number, (iv) the angle of attack, and (iv) the normal and tangential forces.

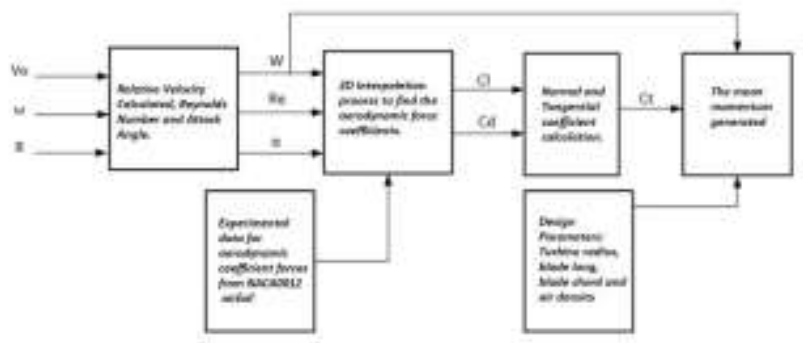

Figure 5 Block diagram of the algorithm Own Elaboration 
Drag and lift coefficients data of the NACA0012 airflow were obtained by experimental data conducted by Sandia Laboratories [13]. Such data is stored in ROM memory in the form of arrays within a function designed to interpolate the $C_{l}$ and $C_{d}$ parameters for a specific angle of attack and Reynolds number. The drawbacks of this method are: (i) the algorithm requires iterations for the calculation of the induction factor to each tube, and (ii) that the calculated average torque is the value of the stationary state response.

The main objectives of the simulation of the algorithm in Matlab are: (i) to analyze the behavior of the average torque in both the highspeed zone and the low-speed zone, this at different speeds with a constant T.S.R. and (ii) to check the behavior of the average torque in a revolution with a constant angle of attack.

\subsubsection{Testing}

The following tests were done to obtain the stationary responses of angular-torque position and angular position-angle of attack, this at different wind speeds with a fixed T.S.R. without modification of the angle of attack: (i) Static open-loop testing with the designed wind turbine, (ii) static closed-loop testing with a proposed control strategy, and (iii) transient response testing with three test input signals.

To obtain these results, the following simulation parameters are established (Table 1): initial angle of attack, number of Stream tubes, wind speed, angular velocity and T.S.R. keeping the T.S.R. fixed and modifying the wind speed and the angular speed of the wind turbine.

\begin{tabular}{|l|r|r|r|r|}
\hline Simulation parameters & Test 1 & Test 2 & Test 3 & Test 4 \\
\hline Initial angle of attack. & $0^{\circ}$ & $0^{\circ}$ & $0^{\circ}$ & $0^{\circ}$ \\
\hline $\begin{array}{l}\text { Number of Stream } \\
\text { tubes. }\end{array}$ & 20 & 20 & 20 & 20 \\
\hline Wind speed. & $5 \mathrm{~m} / \mathrm{s}$ & $10 \mathrm{~m} / \mathrm{s}$ & $15 \mathrm{~m} / \mathrm{s}$ & $20 \mathrm{~m} / \mathrm{s}$ \\
\hline Angular velocity. & $\begin{array}{r}10.5 \\
\mathrm{rad} / \mathrm{s}\end{array}$ & $21 \mathrm{rad} / \mathrm{s}$ & $\begin{array}{r}31.5 \\
\mathrm{rad} / \mathrm{s}\end{array}$ & $42 \mathrm{rad} / \mathrm{s}$ \\
\hline $\begin{array}{l}\text { T.S.R. } \\
\text { (dimensionless) }\end{array}$ & 4.2 & 4.2 & 4.2 & 4.2 \\
\hline
\end{tabular}

Table 1 Simulation parameters at different speeds and with fixed T.S.R.

The parameters described in Table 1 are established to analyze the behavior of the wind turbine at low speeds. Four tests are proposed at different speeds below $20 \mathrm{~m} / \mathrm{s}$ and with a constant T.S.R.
Alternatively, in this first static analysis the test is performed with a pitch angle equal to zero, to analyze the behavior of the vertical axis wind turbine to open loop and locate the values where the torque is maximum and minimum with respect to the angle of attack and the angular position. For this we obtain the graphs of: (i) angular position $\theta$ vs Torque and (ii) angular position $\theta$ vs angle of attack (Figures 69) in all four cases.
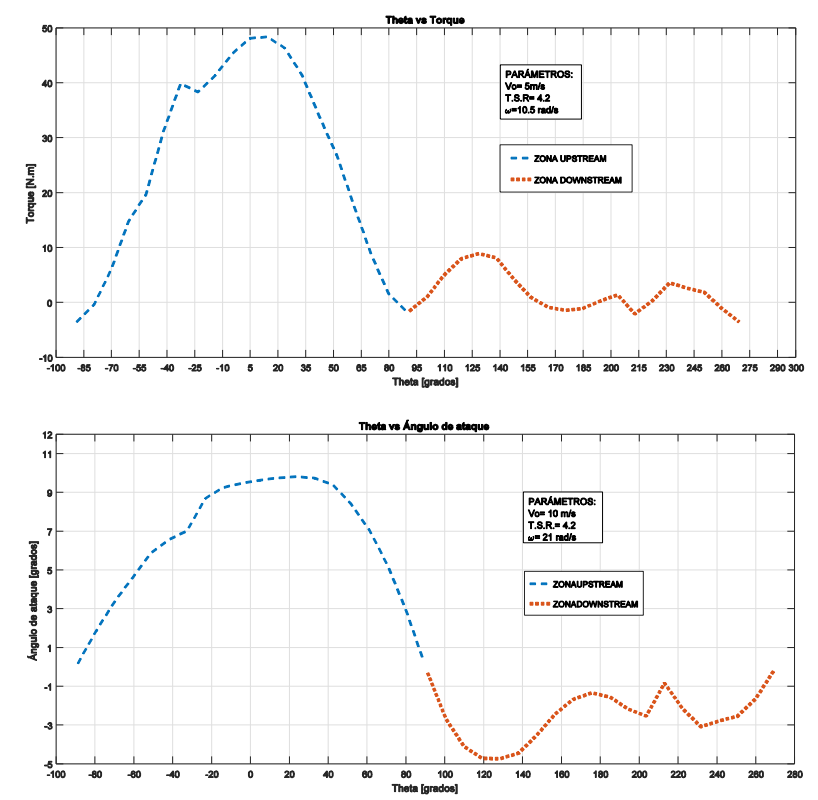

Figure 6 a) Torque Curve vs Angle of Attack and b) a) Theta Curve vs Angle of Attack Test 1

Own Elaboration whit MATLAB
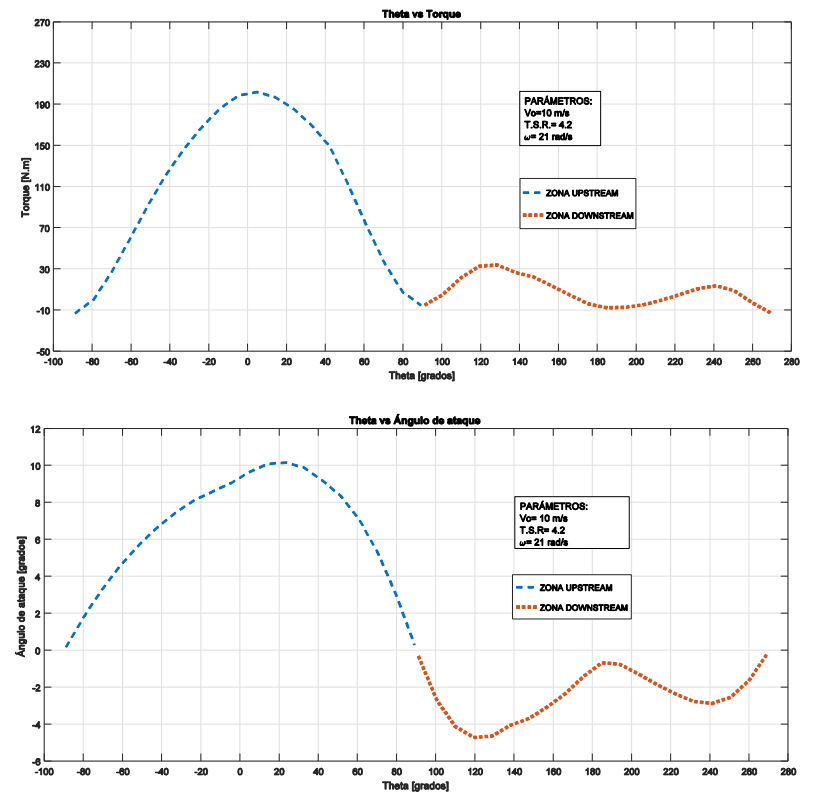

Figure 7 a) Torque Curve vs Angle of Attack and b) a) Theta Curve vs Angle of Attack Test 2

Own Elaboration whit MATLAB 

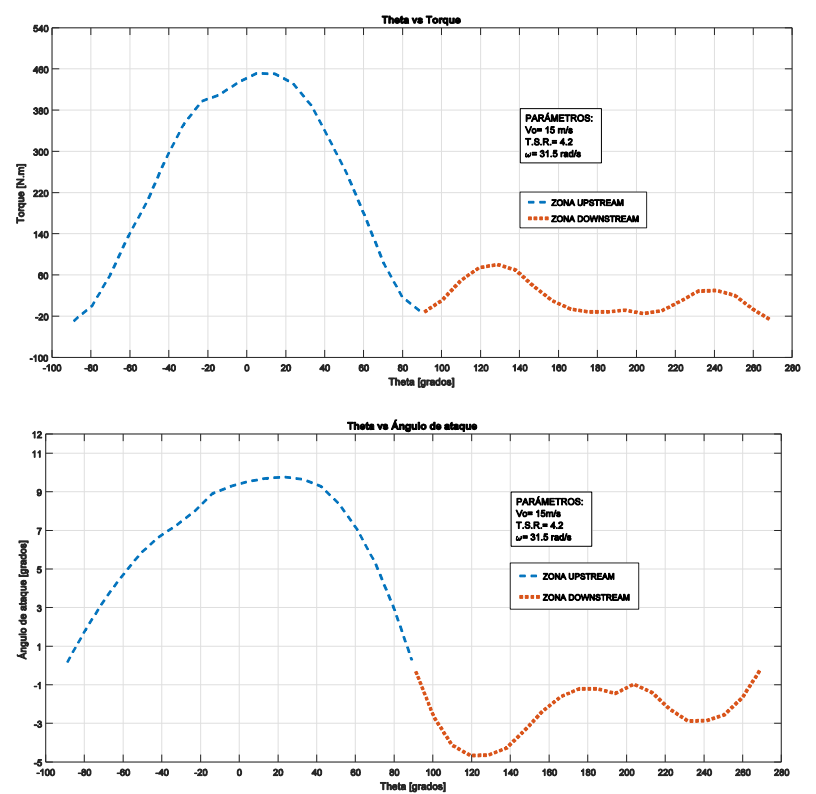

Figure 8 a) Torque Curve vs Angle of Attack and b) Theta Curve vs Angle of Attack Test 3 Own Elaboration whit MATLAB
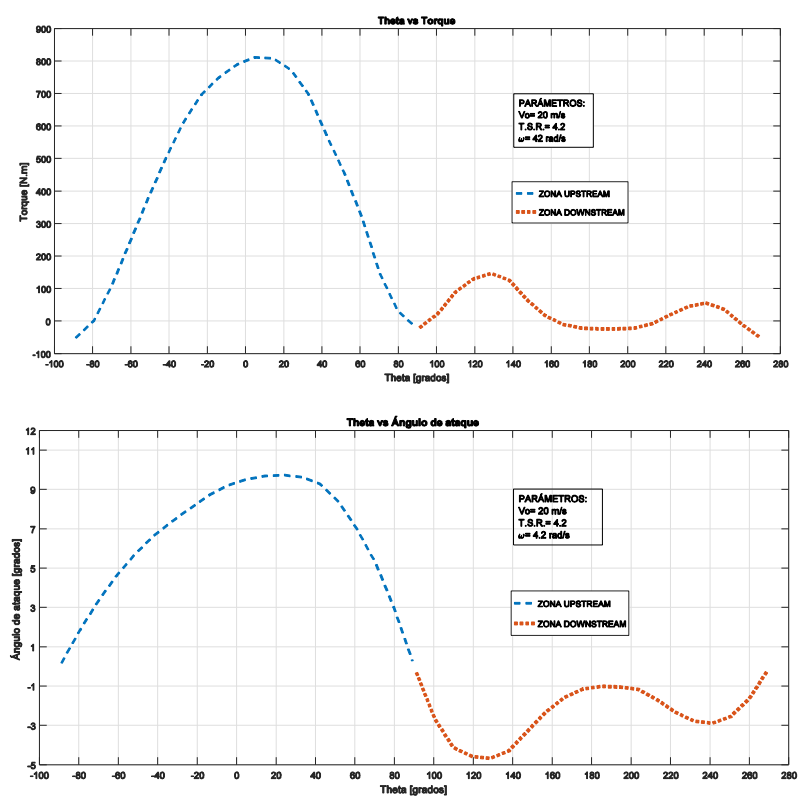

Figure 9 a) Torque Curve vs Angle of Attack and b) Theta Curve vs Angle of Attack Test 3 Own Elaboration whit MATLAB

As can be seen in the Theta vs Torque curves of Figures 6a), 7a), 8a) and 9 a) and the Theta vs Angle of Attack curves of Figures 6b), $7 b), 8 b$ ) and 9b) the shapes of the curves at different speeds are very similar, giving the maximum torque in an angular position of between $0^{\circ}$ and $20^{\circ}$ that correspond to an angle of attack between $9^{\circ}$ and $10^{\circ}$, while the minimum torque occurs in an angular position around $270^{\circ}$ which corresponds to an angle of attack of between $-2^{\circ}$ and $0^{\circ}$.
If the four curves are superimposed on a single graph (Figure 10) this behavior can be seen more clearly and it can also be concluded that: (i) the angle of attack that generates the greatest torque is between $9^{\circ}$ and $10^{\circ}$ while the lowest between $-2^{\circ}$ and $0^{\circ}$, regardless of the wind speed and (ii) the torque generated is proportional to the square of the wind speed. These conclusions with valid with a constant T.S.R. of 4,2 .

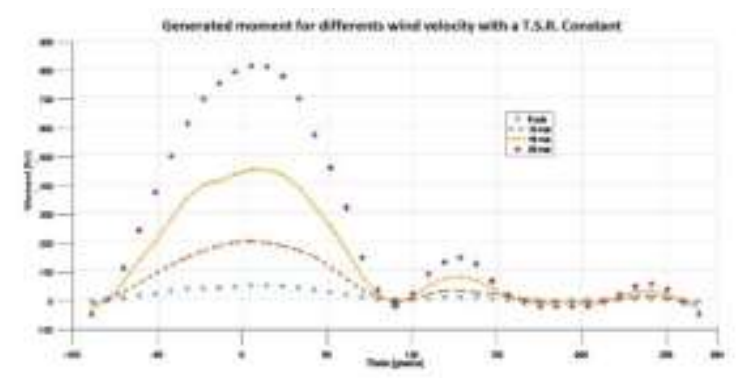

Figura 2 Theta vs torque

Own Elaboration whit MATLAB

\section{3.-Implementation of the simplified nonlinear Rotational Inertia Model}

To perform the dynamic tests, it is proposed a second-order dynamic model of rotational inertia type with viscous friction (Equation 6), where the excitation torque is calculated with the help of a function in Simulink written in MATLAB. The dynamic model is used for both the high and low speed zone.

$\ddot{\theta}(t)=\left(-\frac{B}{J}\right)(\dot{\theta}(t))+\left(\frac{T}{J}\right)$

The algorithm requires as inputs the angular position and velocity generated by Simulink's integrating blocks and wind speed. These inputs are used for the calculation of the relative wind speed, Reynolds number and angle of attack for each angular position.

Subsequently, the system performs a two-dimensional interpolation with respect to the angle of attack and Reynolds number to obtain the drag and lift coefficients of the blade and with it the tangential and normal coefficients in each angular position. To obtain the average torque of the turbine requires the tangential coefficient and design parameters which are: radius of the turbine, length and rope of the blade and the density of the air. 
Finally, the average torque is used in the dynamic model in conjunction with the rotational inertia and viscosity coefficient of the system for the calculation of angular acceleration. This model allows to determine the transient response of the wind turbine and thus analyze the dynamic behavior of the system at different wind speeds. The answers that can be obtained include: (i) the torque generated by each blade and by the wind turbine, (ii) the angular position, (iii) the angular velocity, (iv) the normal force and (v) the tangential force of each blade.

Once the methodology used for the implementation of the static and dynamic models of the wind turbine has been described, in the next chapter, we proceed to propose a prototype of a wind turbine and to carry out tests in simulation of the static and dynamic behavior of said wind turbine.

\section{Static closed-loop testing with a proposed control strategy}

The stationary results obtained in the previous simulations show that the maximum torque is generated with an angle of attack around $10^{\circ}$ and the lowest around $0^{\circ}$, at least for a constant T.S.R. of 4.2. Although different ways can be proposed to increase the torque of the wind turbine, the following is proposed: to keep the angle of attack constant with a value equal to 10 throughout the revolution.

Even though this control strategy can present great practical drawbacks, since they involve an actuator that can rotate $360^{\circ}$ with a speed at least equal to the speed of rotation of the wind turbine, it allows to establish an analytical starting point that manages to weigh quantitatively that so much can be increased the torque produced with this theoretical and ideal strategy. To carry out such a test a modification was made to the algorithm to obtain these curves with a constant angle of attack but calculating the Reynolds number that depends on the local result of the wind speed in the blade in both the high-speed and low-speed areas.

The graphs in Figures 12 and 13 show the comparison of the wind turbine's behavior with a free and forced angle of attack to be constant and equal to $10^{\circ}$. It is evident that under this hypothetical test it is possible to increase the torque produced almost to four times.
Many other strategies can be proposed to increase the efficiency of the wind turbine, for example, one that works differently in the four quadrants of the angular position of the blades and whose control objective is: to move the angle of attack as far away as possible from the minimum value and bring it as close as possible to the maximum value.

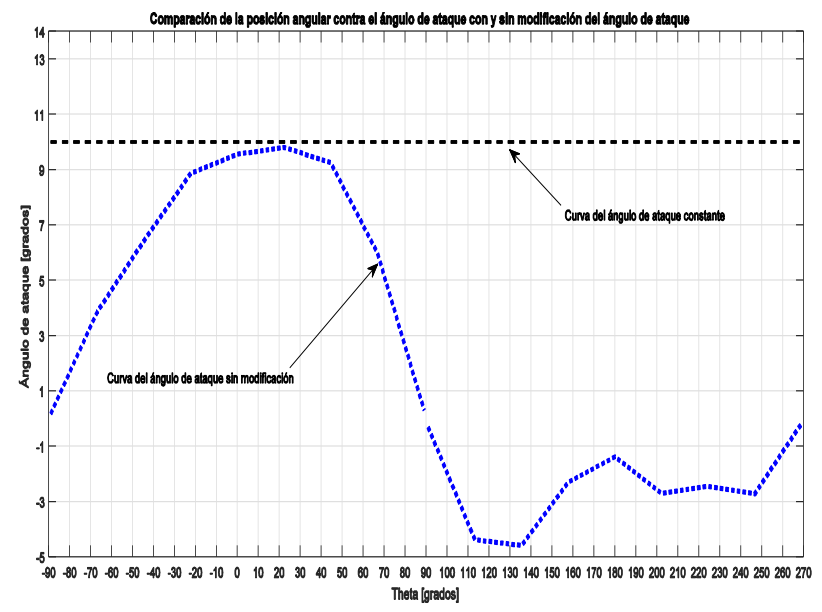

Figure 3 Plot of the angular position against the free and forced angle of attack

Own Elaboration whit MATLAB

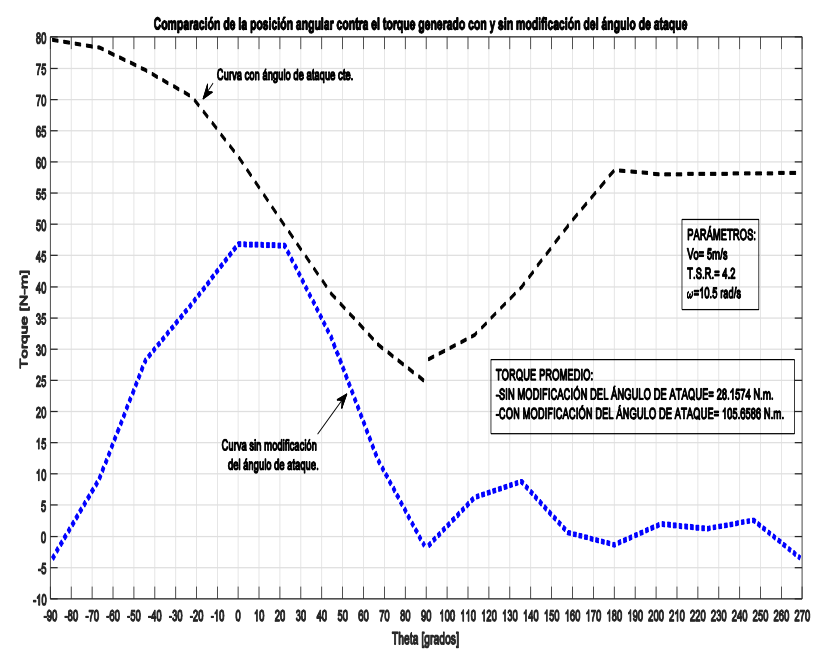

Figure 12 Comparison of average torque with free and forced angle of attack

Own Elaboration whit MATLAB

\section{Transient response tests with two input signals}

This group of tests seek to show, for the first time, the characteristics of the transient response of the wind turbine to two different test inputs, remembering that the input of the wind turbine is the wind speed. The two selected test inputs are: (i) step input (Figure 14) up and down (7), and (ii) sine wave (Figure 21) with a CD component (8).

FRANCO-MARTÍNEZ, David, GARCÍA-BARRERA, Jesús, DÍAZSALGADO, Jorge and HUERTA-CHÁVEZ, Oliver M. Simplified nonlinear rotational inertia model for the simulation and analysis of the characteristics of an unconventional VAWT type wind turbine with variable pitch. Journal of Technological Development. 2021 
The first input signal seeks to simulate how the wind turbine responds from rest to a wind gust of $10 \mathrm{~m} / \mathrm{s}$ with a duration of 4 minutes that then disappears, the second signal seeks to simulate a wind gust that increases and decreases around $6 \mathrm{~m} / \mathrm{s}$ of speed in a periodic way.

$u_{1}(t)=\left\{\begin{array}{cc}0.01 & t<10 \\ 10 & t \geq 10 \\ -10 & t \geq 250\end{array}\right.$

$u_{2}(t)=A \operatorname{sen}(\omega t)+\varphi$

With $A=5, \omega=0.062831$ and $\varphi=6$. To obtain these dynamic responses, the positions, and angular velocities of each of the blades must also be established:

$\theta_{1}=\dot{\theta}_{1}=\dot{\theta}_{2}=0$

$\theta_{2}=180^{\circ}$

The responses with the input $\mathrm{u}_{1}$ (Figures 14-15) show: (i) a variant torque with area under the positive curve (Figures 18 and 21), (ii) a transient ascent response with settlement time of approximately 35 seconds. (Figures 19 and 20), (iii) a periodic stationary response (Figures 19 and 21) and (iv) a transient descent of approximately 200 s. (Figs. 19 and 20). As can be seen there is a difference of almost 6 times the transitory of descent with respect to the one of rise. This can be explained because there is a singularity when the input velocity becomes null since the T.S.R becomes infinite. To minimize this effect the input is not made zero, but equal to $0.01 \mathrm{~m} / \mathrm{s}$, however, even with this small value the difference between up and down settlement time is noticeable.
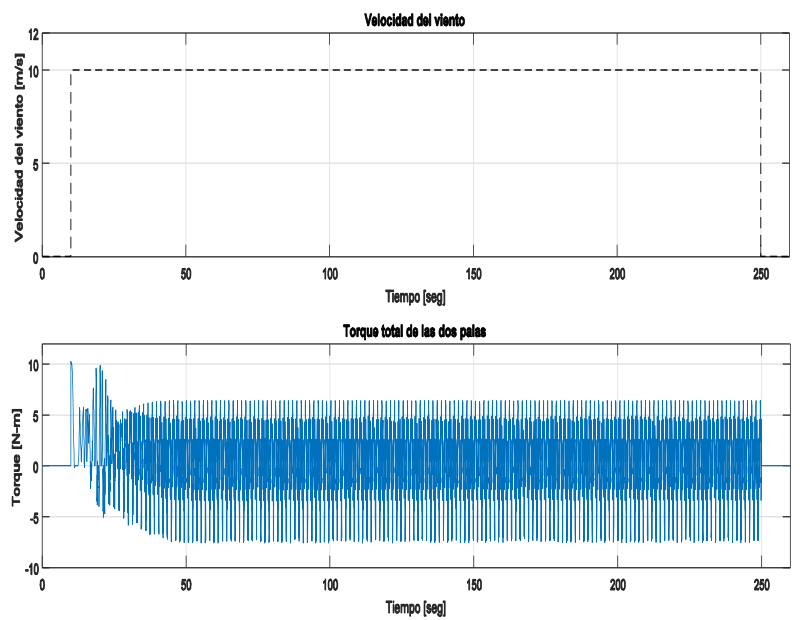

Figure 13 Graphs of wind speed $\mathrm{u}_{1}$ and total torque Own Elaboration whit MATLAB

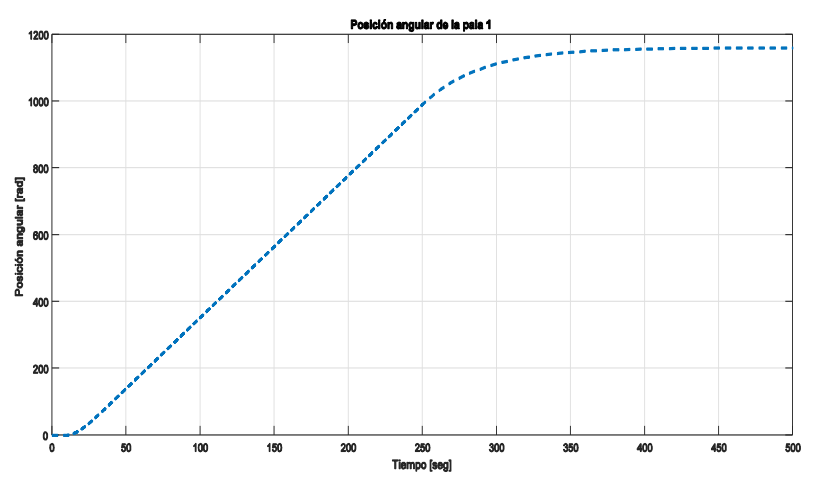

Figure 4 Angular position of blade 1 generated with input $\mathrm{u}_{1}$

Own Elaboration whit MATLAB

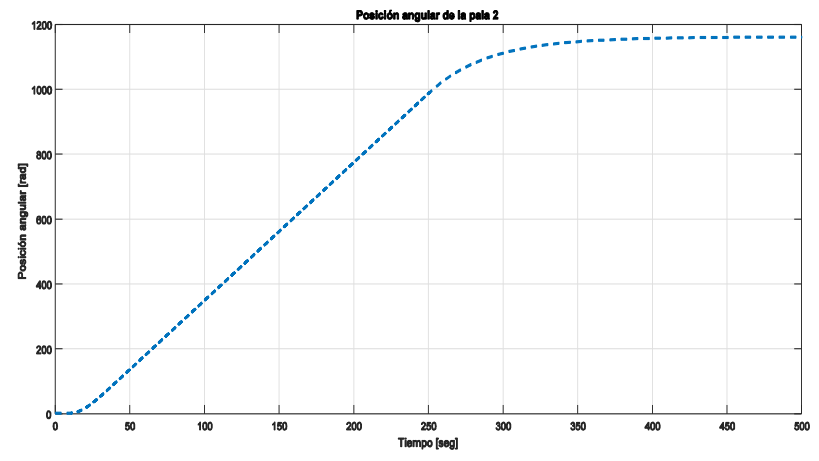

Figure 5 Angular position of blade 2 generated with input $\mathrm{u}_{1}$

Own Elaboration whit MATLAB

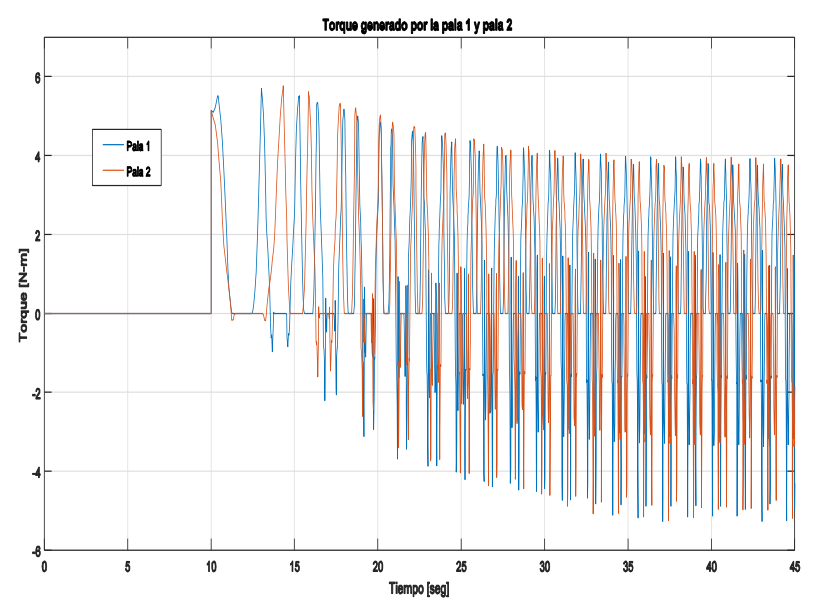

Figure 6 Comparison of the torque generated from blade 1 and 2 with input $\mathrm{u}_{1}$

Own Elaboration whit MATLAB 


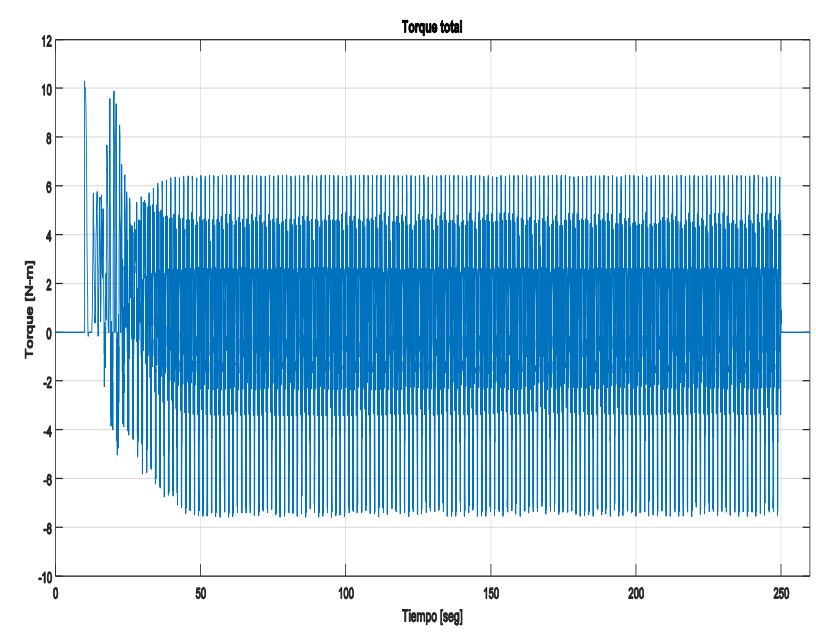

Figure 7 Total generated torque with input $\mathrm{u}_{1}$. own elaboration whit MATLAB

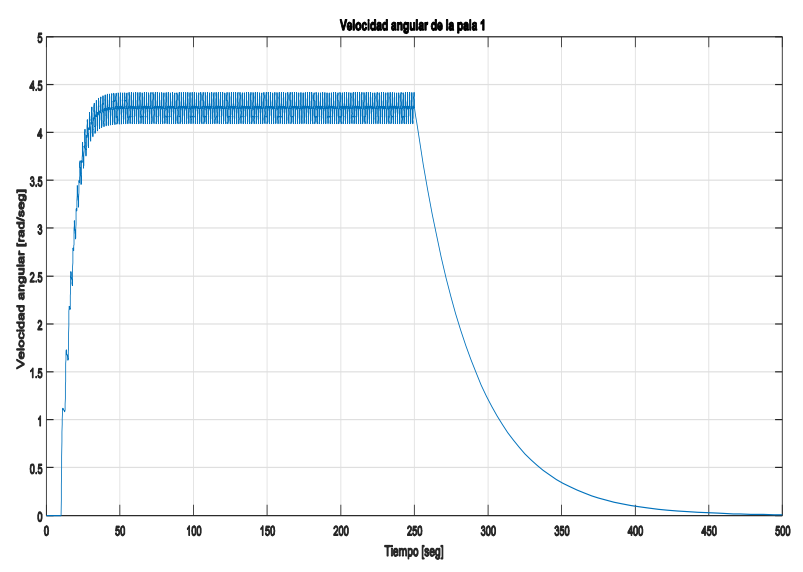

Figure 8 Angular velocity of blade 1 generated with input $\mathrm{u}_{1}$

Own Elaboration whit MATLAB.

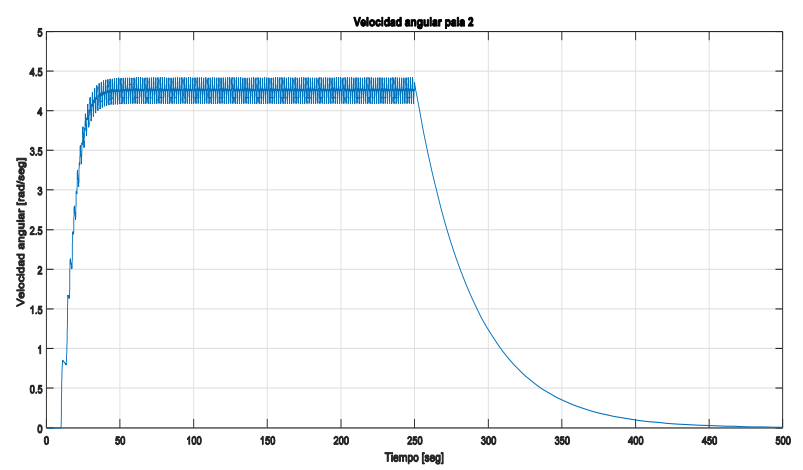

Figure 9 Angular velocity of blade 2 generated with input $\mathrm{u}_{1}$

Own Elaboration whit MATLAB

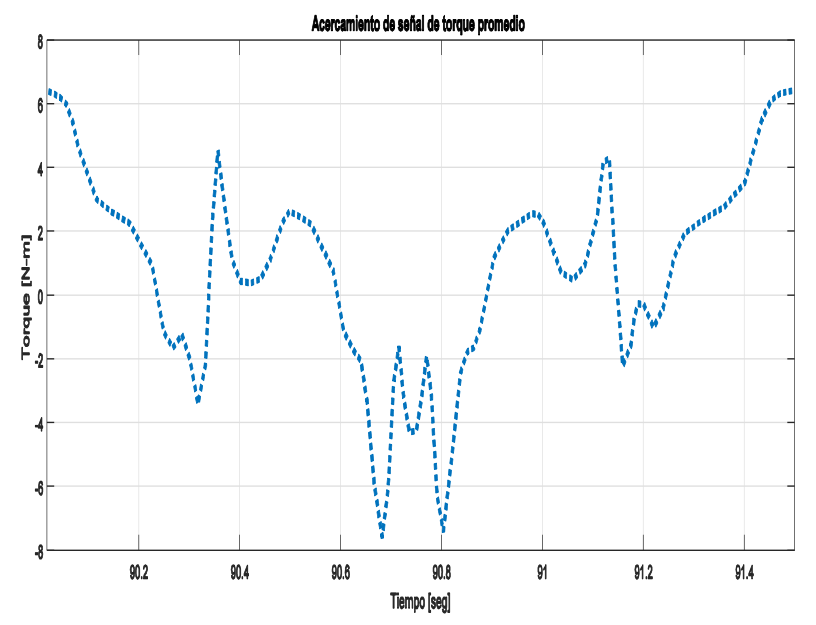

Figure 20 Approximation of the total torque in the standing state with the input $\mathrm{u}_{1}$

Own Elaboration whit MATLAB

In Figure 18 showed the shape of the test 2 input, where it is clearly noted that the output maintains the oscillation period from its inputs and the quadratic relationship between wind speed and torque described with the help of the static model. This shows that the settlement time is inherent in the system and independent of the input. In the stationary state there is also an average torque with a positive part which explains the variation of the speed within a minimum range (of $0.75 \mathrm{rad} / \mathrm{s}$ ) and maximum (of $5 \mathrm{rad} / \mathrm{s}$ ) in the stationary state (Figures 10 ). The angular position varies in the period dictated by the input (Figures 23-24) as expected. Another very noticeable aspect is that the torques of blades 1 and 2 cancel out for certain time intervals; for example, for the interval of 12 to 17 seconds (Figure 25) which causes the angular velocity to decrease for each blade and therefore the torque generated.
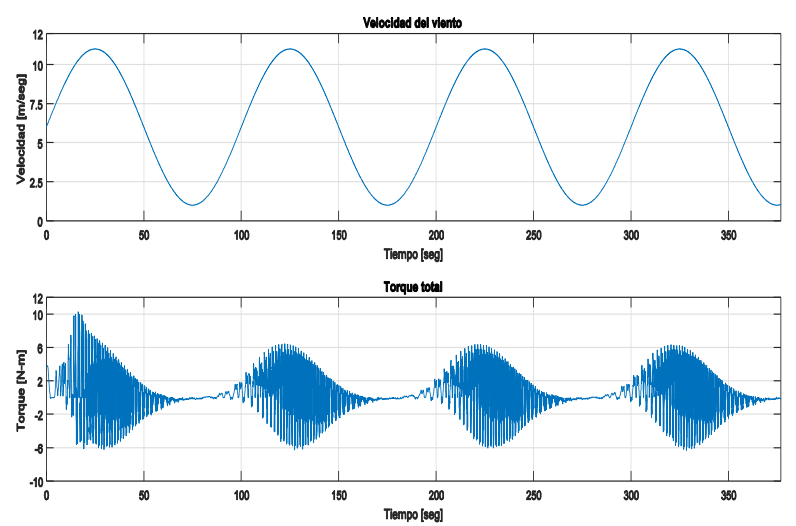

Figure 21 Velocity plots with input $\mathrm{u}_{2}$ Own Elaboration whit MATLAB 


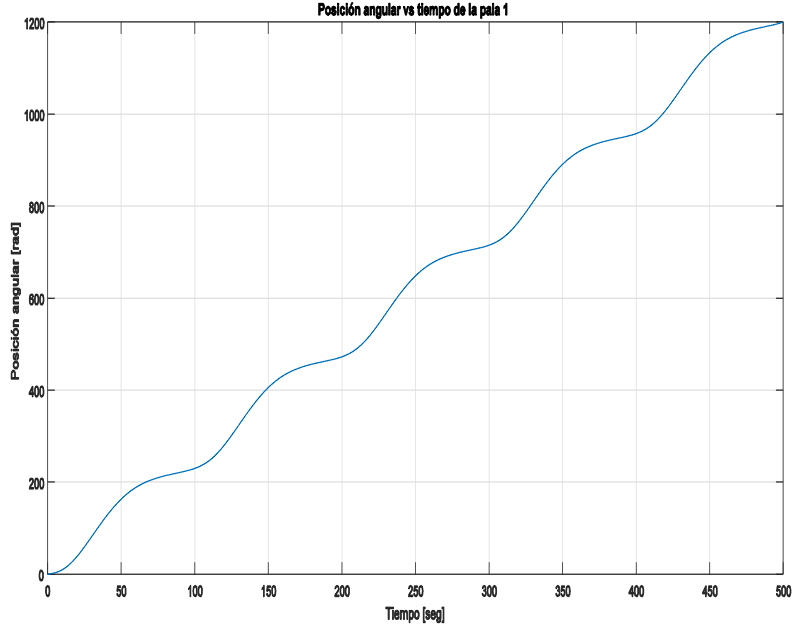

Figure 22 Angular position of blade 2 generated with input $\mathrm{u}_{2}$

Own Elaboration whit MATLAB

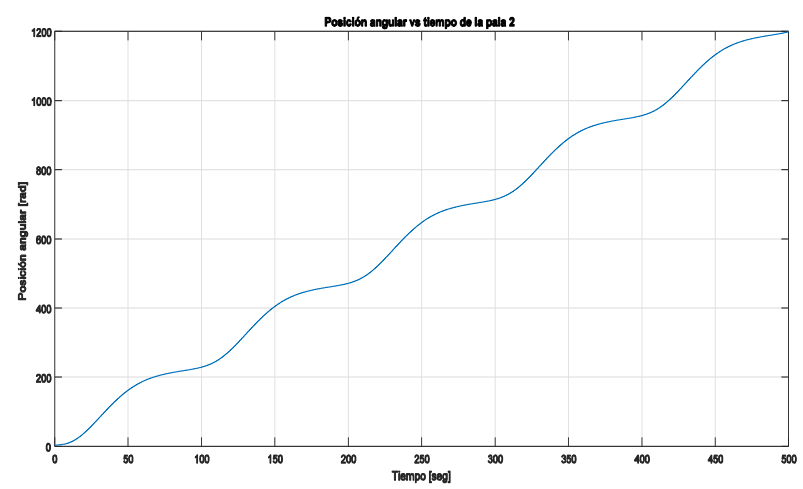

Figure 23 Angular position of blade 2 generated with input $\mathrm{u}_{2}$

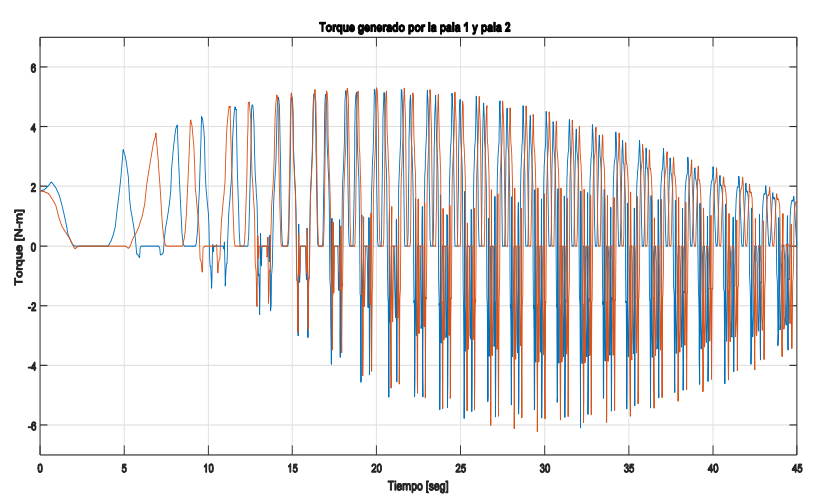

Figura 24 Comparación del torque generado de la pala 1 y 2 con la entrada $\mathrm{u}_{2}$

Own Elaboration whit MATLAB

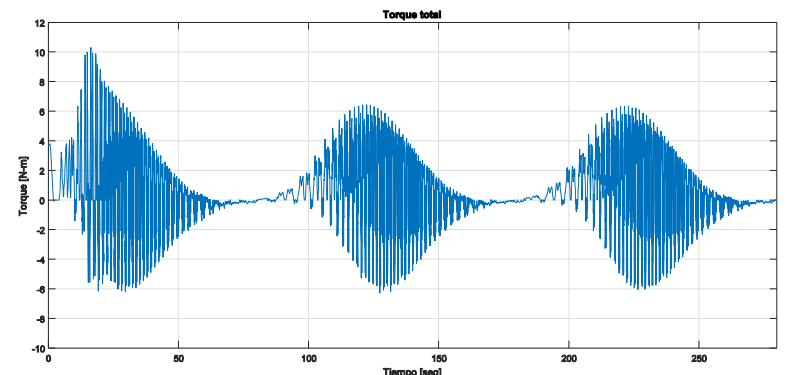

Figura 25 Torque generado total con la entrada $\mathrm{u}_{2}$ Own Elaboration whit MATLAB

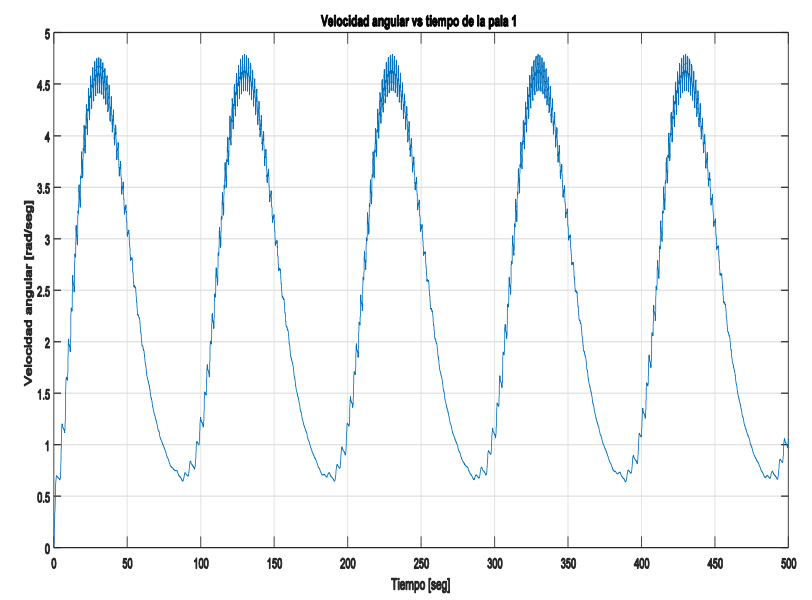

Figura 26 Velocidad angular de la pala 1 generada con la entrada $\mathrm{u}_{2}$

Own Elaboration whit MATLAB

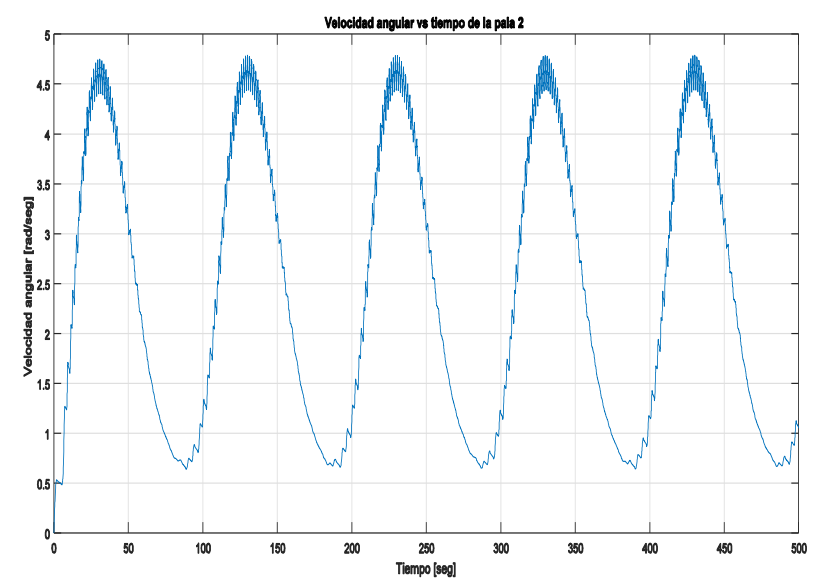

Figure 10 Angular velocity of blade 2 generated with input $\mathrm{u}_{2}$

Own Elaboration whit MATLAB

\subsection{Analysis of the graphs obtained with sinusoidal input}

This analysis shows that as with step entry the system tends to enter its area in a stationary state in approximately 35 seconds (Figure 28). This gives us a better idea of the behavior that the wind turbine should have with this type of wave and these parameters.

FRANCO-MARTÍNEZ, David, GARCÍA-BARRERA, Jesús, DÍAZSALGADO, Jorge and HUERTA-CHÁVEZ, Oliver M. Simplified nonlinear rotational inertia model for the simulation and analysis of the characteristics of an unconventional VAWT type wind turbine with variable pitch. Journal of Technological Development. 2021 
Regardless of this, the purpose of this test is to simulate by means of a sinusoidal input the behavior that the wind turbine would have before high and low levels of wind speed.

Based on the graphs (Figures 24 and 25) even though the input has high and low wind speed (Figure 23) the position of the blades continues to grow, in other words, the wind turbine continues to rotate. On the other hand, the angular velocity reaches a maximum of 5 $\mathrm{rad} / \mathrm{sec}$ and a minimum of $0.75 \mathrm{rad} / \mathrm{sec}$, this shows that, if indeed the wind turbine does not stop turning, it has high and low speeds, but the wind turbine continues to rotate.

In addition, total torque is proportional to wind speed (Figure 26). Another important aspect is that the torques of blades 1 and 2 are cancelled for certain time intervals such as for the interval of 12 to 17 seconds (Figure 25) what causes is that the angular velocity decreases for each blade and therefore the torque.

\section{Comparison of stationary responses with static and dynamic models}

To equate the two models proposed and implemented in this work on equal terms, this last test is proposed: the comparison of stationary responses with static and dynamic models. It should be noted that a perfect quantitative agreement is not expected to be found since the models differ in the number of tubes considered for the calculation of the parameters of the area of influence of the blades; while the dynamic model considers a single pipe segment, the static model considers 20 .

The 26 shows a cycle of the stationary responses obtained with the static and dynamic models respectively, and Table 5 shows the maximum, minimum and average torques of each of the responses. It can be observed in the stationary values that there is a quantitative agreement in the three torques considered.

A great qualitative agreement can also be observed since the curves present very similar regions: (i) two areas with predominantly positive torque at the beginning and end of each cycle and (ii) an area with predominantly negative torque values in the middle part of the cycle.
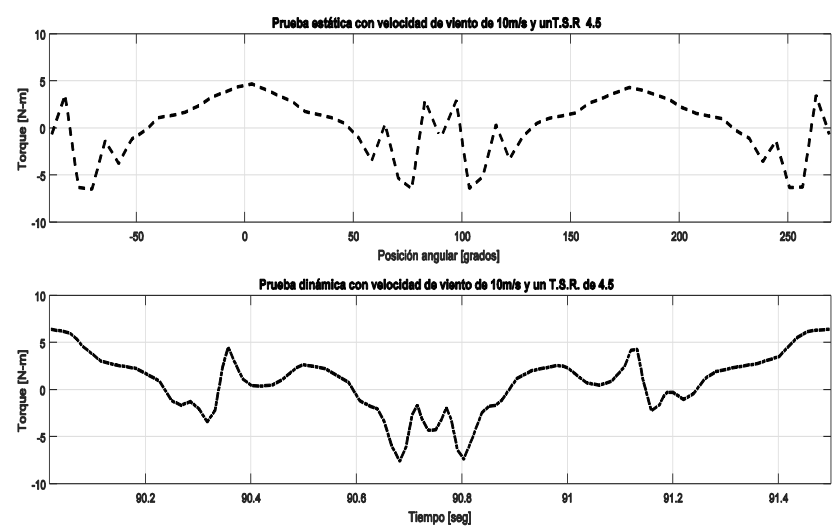

Figure 28 Comparison of torque in a stationary state cycle with static and dynamic models with a wind speed of $10 \mathrm{~m} / \mathrm{s}$

Own Elaboration whit MATLAB

\begin{tabular}{|c|c|c|c|}
\hline Model & $\begin{array}{l}\text { Average } \\
\text { torque }\end{array}$ & $\begin{array}{l}\text { Maximum } \\
\text { torque }\end{array}$ & $\begin{array}{l}\text { Minimum } \\
\text { torque }\end{array}$ \\
\hline Static & $1.0678 \mathrm{Nm}$ & $5.0 \mathrm{Nm}$ & $-7.0 \mathrm{Nm}$ \\
\hline Dynamic & $1.2488 \mathrm{Nm}$ & $6.2 \mathrm{Nm}$ & $-7.5 \mathrm{Nm}$ \\
\hline
\end{tabular}

Table 2 Comparison of the static and dynamic parameters of the static and dynamic models

Own Elaboration

\section{Conclusions}

The aim of the present research was to show the modeling, simulation, and analysis of the aerodynamic characteristics of the main components of a vertical axis wind turbine. It was reached by achieving the initial objective, which was to establish and implement in simulation two mathematical models of the vertical axis wind turbine to obtain the stationary and transient state responses.

The results from the analysis of the stationary and transient responses with both models allow to conclude that: (i) the torque generated is proportional to the square of the wind speed, (ii) there are attack angles where the generated torque is minimized and maximized, (iii) for a vertical axis wind turbine with two straight blades there are certain time intervals where there is an cancellation of the torques generated, (iv) the transient response is inherent to the physical parameters of the wind turbine and independent of the input and (v) for periodic signals, the output of the system retains the oscillation frequency given by the input. 
Alternatively, simulations were only made with a vertical axis wind turbine with two blades, being that the software designed can be easily modified to consider a greater number of blades. In addition to the fact that it is possible to modify it suitably for the inclusion of a straight blade wind turbine with central plunger.

Other aspects to improve the algorithms are: (i) the inclusion of the model with multiple current tubes in the dynamic model, (ii) the inclusion of the pitch angle directly in the numerical calculations of the simulation, (iii) the analysis of the number of tubes sufficient for a correct decrease of the error in the numerical approximation and (iv) the inclusion of a greater number of points in the table of angle of attack and number of Reynolds for the calculation of the coefficients of lift and drag to improve the accuracy of the numerical calculations of the algorithm

\section{Acknowledgements}

To the Program of Support to Research and Technological Innovation Projects PAPIIT with file numbers IN113921 and IN118820. Likewise, to CONACYT chairs and COMECYT Chairs. Along with TESE facilities for aerodynamic testing and computational resources.

\section{References}

[1] Villar J.A., Roberto M., Boscato, Da Silva G.C., Konzen G. (2008) Performance evaluation of the next generation of small vertical axis wind turbine, Pontifical Catholic University of Rio Grande do Sul, Brazil.

[2] Sathyajith M., Geeta S. P. (2011)., Advances in Wind Energy Conversion Technology, Spinger, Berlin.

[3] Madsen H. A., Thomsen K. (2011) Analysis of Wind Turbine Loads, Technical University of Denmark, Denmark.

[4] Aslam Bhutta M. M., Hayat N., Farooq A. U., Ali Z., Jamil Sh. R., Hussain Z. (2011) Vertical axis wind turbine: A review of various configurations and design techniques, Renewable and Sustainable Energy Reviews, 1926-1939.
[5] Nagare P., Shettigar R., Nair A., Kale P., Nambiar P. (2015), Vertical Axis Wind Turbine, $1-6$

[6] Chaichana T, Chaitep (2010) S. Wind power potential and characteristic analysis of Chiang Mai, Thailand. Mechanical Science and Technology; 24:1475-9.

[7] Islam M, Ting D. S.-K., Fartaj Amir. (2006) Review of Aerodynamic models for Darrieustype straight-bladed vertical axis wind turbines, Elsevier, University of Windsor, Windsor, Ont., Canada.

[8] Tong, W. (2010). Fundamentals of wind energy. In W. Tong, Wind power generation and wind turbine design (p. 112). WIT Press.

[9] Spera, D. (2009). Wind Turbine Technology, fundamental concepts of wind turbine engineering. ASME Press.

[10] Paraschivoiu, I. (2002). Wind Turbine Design With Emphasis on Darrieus Concept. Presses Internationales Polytechnique.

[11] Templin, R. (1974). The Elements of Airfoil and Airscrew Theory. Cambridge University Press, second edition.

[12] Castillo J. (2011) Small-Vertical Axis Wind Turbine Design, Bachelor's Thesis, Tampereen ammattikorkeakoulu, Finlandia.

[13] Sheldahl R.E., Klimas P C. (1981) Aerodynamic Characteristics of Seven Symmetrical Airfoil Sections Through 180dregree Angle of Attack for use in Aerodynamic Analysis of Vertical Axis Wind Turbines, Sandia National Laboratories, Alburquerque, New Mexico.

[14] Li-xun Z., Ying-bin L., (2014) Effect of blade pitch angle on aerodynamic performance of straight-bladed vertical axis wind turbine, College of Mechanical and Electrical Engineering, Harbin Engineering University, China , 2014.

[15] Islam M., Ting D. S.-K., Fartaj Amir. (2006) Aerodynamic models for Darrieus-type straight-blade vertical axis wind turbines, University of Windsor, Windsor, Ont., Canada. 
[16] Li-xun Z, Pei Y. (2015) Design and Implementation of Straight-blade Vertical Axis Wind Turbine with Collective Pitch Control, College of Mechanical and Electrical Engineering, Harbin Engineering University, China.

[17] Li-xun Z., Liang Y. (2012) Vertical Axis Wind Turbine with Individual Active Blade Pitch Control, College of Mechanical and Electrical Engineering, Harbin Engineering University, China.

[18] Li-xun Z., Ying-bing L. (2012) Effect of blade pitch angle on aerodynamic performance of straight-blade vertical axis wind turbine.

[19] Zhang Q., Chen H. (2010) Modeling and Simulation of Two-Leaf Semi-rotary VAWT, School of Electronic and Information Engineering Zhongyuan Institute of Technology, Zhongyuan Middle Road 41, Zhengzhou, China.

[20] Pawsey N. C. K. (2002) Development and evaluation of passive variable-pitch vertical axis wind turbines, PhD Thesis, School of Mechanical and manufacturing Engineering, The University of New South wales, Australia, 2002.

[21] Hantoro R., Utama I. K. A. P., Erwandi and Sulisetyono A. (2011) An Experimental Investigation of Passive Variable-Pitch VerticalAxis Ocean Current Turbine, ITB J. Eng. Sci, vol. 43, pp. 27-40, 2011.

[22] Hwang I. S., Min S. Y., Jeong I. O., Lee Y. H. and Kim S. J. (2006) Efficiency improvement of a new vertical axis wind turbine by individual active control of blade motion, Smart Structures and Materials 2006 - Smart Structures and Integrated Systems, vol. 6173. 